\title{
Caminhos cruzados
}

Vander Madeira ${ }^{1}$

RESUMO: Este trabalho pretende mostrar como Literatura, História, Memória e Testemunho se cruzam no percurso de Euclides da Cunha e Ferreira de Castro na Amazônia. A "terra sem história" e os homens sem voz se fazem presentes nos Ensaios Amazônicos (1905) e n'A selva (1930); mais do que assuntos, são motivos da produção textual. Procura-se demonstrar como os dois autores, movidos por objetivos distintos acabam por apresentar semelhanças de abordagem.

ABSTRACT: This paper discusses the way Literature, History, Memory, and testimony intertwine as Euclides da Cunha and Ferreira de Castro explore the Amazon. The "land with no history" and the voiceless men feature prominently in Ensaios Amazônicos (1905) and in Jungle (1930). More than themes, these are motifs for textual production. This paper examines how Euclides da Cunha and Ferreira de Castro, aiming at different objectives, end up choosing similar approaches.

PALAVRAS-CHAVE: Selva, Amazônia, Euclides, Castro, Testemunho

KEYWORDS: Jungle, Amazon, Euclides, Castro, Testimony

Literatura, História, Memória e Testemunho se cruzam no percurso de Euclides da Cunha e Ferreira de Castro na Amazônia. A "terra sem história" e os homens sem voz se fazem presentes nos Ensaios Amazônicos (1905) e n'A selva (1930); mais do que assuntos, são motivos da produção textual.

A viagem de Euclides da Cunha à Amazônia em 1905, da qual se originaram diversos ensaios e o projeto, não realizado, de um volume dedicado à região, deu-se por motivos oficiais, Euclides foi o chefe da Comissão Mista Brasileiro-Peruana de Reconhecimento do Alto Purus, cujo objetivo era estabelecer marcos, elaborar mapas e estabelecer fronteiras.

A chegada de Ferreira de Castro ao Pará, na terceira classe de um navio, deu-se no ano de 1911, nessa época ele tinha onze anos. Como muitos portugueses, fugia das difíceis condições econômicas de sua aldeia. Foi mais um, dos milhares de migrantes e imigrantes, seduzido pelos sonhos de enriquecimento gerados pelo auge do ciclo da borracha, 18801910.

\footnotetext{
${ }^{1}$ Mestrando em Estudos comparados de Literaturas de Língua Portuguesa, FFLCH-USP. Pesquisa: A selva: viagem de descobrimento. E-mail: vandermadeira@hotmail.com
} 
A selva, romance publicado em 1930, não se constitui na biografia de Ferreira de Castro, mas, como ele mesmo afirma: "não é menos verdadeiro também que a ficção se tece sobre um fundo vivido dramaticamente por seu autor". A vida na floresta deixou marcas profundas no escritor, como ele declara em Pequena história de "A selva", texto que aborda processo de criação do romance:

[...] não ocorre uma única semana sem eu sonhar que regresso à selva, como, após a evasão frustrada, se volta, de cabeça baixa e braços caídos, a um presídio. E quando o terrível pesadelo me faz acordar, cheio de aflição, tenho de acender a luz e de olhar o quarto até me convencer de que sonho apenas _ eu que, nos derradeiros tempos, tanto desejo retornar à selva, para a ver um último dia e dela me despedir para sempre. (CASTRO, 1972, p.25)

\section{Intenções e testemunhos}

Em 1904, ainda pleiteando lugar na expedição governamental, Euclides diz em carta ao amigo José Veríssimo: “[...] é um meio admirável de ampliar a vida, o de torná-la útil e talvez brilhantíssima. Sei que farei muito". (GALVÃO e GALLOTTI, 1997, p. 208) Na mesma carta ele diz de seu intento: "revelar os prodígios da nossa terra". Após o sucesso de Os sertões, Euclides tinha a intenção de produzir outra obra de "revelação do Brasil": Um paraíso perdido. Durante o ano de 1905, período de seu deslocamento pela floresta, vários dos textos que comporiam a obra projetada são publicados na imprensa. A partir de 1906, já de volta ao Rio de Janeiro tem início a redação final do volume, mas o assassinato do autor em 1909 impediu sua finalização.

Também Ferreira de Castro enuncia sua intenção ao publicar $A$ selva, como registra o pórtico do romance:

[a]os anônimos desbravadores, que viriam a ser meus companheiros, meus irmãos, gente humilde que me antecedeu ou acompanhou na brenha, gente sem crônica definitiva [...] Devia-lhes este livro, que constitui um pequeno capítulo da obra que há de registrar a tremenda caminhada dos deserdados através dos séculos, em busca de pão e de justiça. (CASTRO, 1972, p.21)

As afirmações e escolhas formais dos autores encaminham as obras para a linha do testemunho, pois ambos dizem daquilo que viram e viveram. 
O testemunho quer-se idôneo, quer-se verídico, pois aspira a certo grau de objetividade. Como tal, casa memória individual com história.

Mas o testemunho também se sabe obra de uma testemunha, que é sempre um foco singular de visão e elocução. Logo, o testemunho é subjetivo e, por esse lado, se aparenta com a narrativa literária em primeira pessoa.

O testemunho vive e elabora-se em zona de fronteira. As suas tarefas são delicadas: ora fazer a mimese de coisas e atos apresentando-os "tais como realmente aconteceram" (conforme a frase exigente de Ranke), e construindo, para tanto, um ponto de vista confiável ao suposto leitor médio; ora exprimir determinados estados de alma ou juízos de valor que se associam, na mente do autor, às situações evocadas. (BOSI, 2002, p.222)

As lembranças da vida na selva perseguem Ferreira de Castro na forma de pesadelos, mas o autor nos revela uma grande contradição, o medo do retorno e a vontade de voltar ao seringal. A atração e a repulsa poderiam ter dado origem às "Memórias do cárcere amazônico", testemunho em primeira pessoa de um drama vivido. No entanto a opção por um distanciamento, obtido por uma narração em terceira pessoa, amplia a dimensão coletiva do narrado e extrapola os limites da memória. A autobiografia, ainda que se saiba do peso da subjetividade na elaboração do texto, teria um compromisso com a "realidade" maior do que a ficção. Se assim considerarmos, a opção de Ferreira de Castro possibilita a superação do limite imposto pelo vivido, permite preencher as falhas da memória com outra matéria.

Ensaio, por sua vez, tem experiência, reflexão, tentativa e pensamento, bem como "rápida apresentação de um assunto, sem grande desenvolvimento" como algumas acepções possíveis. Os Ensaios amazônicos são o resultado da experiência euclidiana na selva, são as impressões do autor sobre o objeto vislumbrado. Sendo Euclides um estudioso, suas impressões são confrontadas com amplo conjunto de informações anteriormente coletadas, são comparadas com outras experiências e outros relatos.

Tanto A selva quanto os Ensaios amazônicos comportam a marca da intencionalidade de seus autores.

Euclides milita no grupo dos que buscam a integração do variado espaço geográfico brasileiro. Espaço que deve ser conhecido e ocupado por brasileiros. Vale lembrar o seu registro de que, mesmo entre os milhares de estrangeiros instalados em Manaus e Belém, o sotaque brasileiro se destacava. Na mesma linha, se a Amazônia era uma "terra sem história”, ele não estava disposto a permitir que assim continuasse. A terra que ele viu estava a ser ocupada pelos sertanejos, deslocados pela conjunção da seca no Nordeste, o sonho de uma vida melhor e a necessidade de braços para os empreendimentos econômicos. 
Mas também por levas de estrangeiros, como ele percebe e informa. Na Amazônia, Euclides testemunha e vive o confronto entre a vontade do homem e a resistência da natureza. Os Ensaios apresentam uma reflexão sobre a terra e as dificuldades do homem no processo de ocupação. A missão de diplomata/demarcador lhe propicia a experiência de percorrer o espaço desconhecido a ser incorporado ao nosso mapa. A experiência de escritor e a publicação continuada dos ensaios propiciam os meios para atingir um outro fim, dar a conhecer uma parte do Brasil cuja fronteira encontrava-se indefinida e, portanto, em perigo. "Além disso, se as nações estrangeiras mandam cientistas ao Brasil, que absurdo haverá no encarregar-se de idêntico objetivo um brasileiro?" (GALVÃO e GALOTTI, 1997, p.208)

As intenções de Ferreira de Castro vão do alívio de um sofrimento permanente, manifestado nos pesadelos, ao já referido testemunho/denúncia da degradação humana que ele presenciara. $\mathrm{O}$ autor se apresenta imbuído do objetivo de transformar a realidade, de dar voz aos que seduzidos pelos sonhos de riqueza, pelas falsas promessas ou por pura necessidade, se enredavam na máquina econômica da extração de borracha. Ao mesmo tempo em que, como um discípulo de Heródoto, ele escreve para evitar que a história daqueles homens caia no esquecimento, pode-se dizer que Ferreira de Castro elabora seu trauma, revelado pelos pesadelos.

O Trauma é a ferida aberta na alma, ou no corpo, por acontecimentos violentos, recalcados ou não, mas que não conseguem ser elaborados simbolicamente, em particular sob a forma de palavra, pelo sujeito. (GAGNEBIN, 2006, p.110)

O romance dá voz ao autor e aos seringueiros silenciados por sua condição humilde, sujeitos cuja existência está registrada nas histórias oficiais apenas em números imprecisos, apesar de grandiosos.

Não há estatísticas seguras acerca do número de nordestinos que se dirigiram para a Amazônia desde o final do século XIX até o início do século XX. Celso Furtado calcula que o número não tenha sido inferior a meio milhão de pessoas. (PRADO, 1989, p. 291)

Eduardo Galeano informa que "em 1878, dos oitocentos mil habitantes do Ceará, 120 mil marchavam rumo ao rio Amazonas, porém menos da metade pôde chegar" (GALEANO, 1998, p.100), pois os outros sucumbiram à fome e às doenças. Para se ter 
idéia de as estatísticas sobre o número de migrantes é impreciso, a hipótese sobre o número de mortos na floresta, indicada por Galeano, é semelhante ao número mínimo de migrantes levantada por Celso Furtado.

Ao se refletir sobre a escolha de Ferreira de Castro ter recaído sobre o romance, em lugar da autobiografia, pode-se dizer que não é a história de um só homem o que se deseja contar, o testemunho que se quer dar não é o de que o meio rouba a alma ao homem, como vemos no romance de Carlos de Vasconcelos, outro autor a escrever sobre a saga dos nordestinos na floresta. O que Castro faz, pagando sua dívida moral, é inserir os anônimos nas crônicas, na história. Em dupla tarefa, ele luta para que não sejam esquecidos aqueles cuja existência era, na verdade, ignorada.

Também Euclides da Cunha contribui para essa inserção, tanto ao denunciar o processo de escravização dos trabalhadores pelos patrões, quanto ao transformá-los em tema de um de seus ensaios mais famosos.

Em Judas Asverus, Euclides conta como "no Sábado de Aleluia os seringueiros do Auto Purus desforram-se de seus dias tristes." (CUNHA, 1966, p.263) Nesse dia, os seringueiros, com todos os cuidados possíveis, dão-se à tarefa de construir o seu boneco de Judas. O resultado do trabalho "É um doloroso triunfo. O sertanejo esculpiu o maldito à sua imagem. Vinga-se de si mesmo: pune-se afinal, da ambição maldita que o levou àquela terra" (CUNHA 1966, p.266)

Depois de pronto, o boneco é colocado em uma embarcação e lançado em viagem rio abaixo, onde será saudado com tiros e pedradas e receberá a companhia de outros monstros da mesma espécie, até desaparecer levado pela correnteza. O autor d'Os sertões assinala como a festa de um dia contrasta e ironiza a existência cotidiana daqueles homens, como o sertanejo

desafronta-se da fraqueza moral que lhe parte os ímpetos de rebeldia recalcando-o cada vez mais ao plano inferior da vida decaída onde a credulidade infantil o jungiu, escravo, à gleba empantanada dos traficantes que o iludiram. (CUNHA, 1966, p.266)

Os caminhos de Euclides e de Ferreira de Castro se cruzam na revelação de uma existência condenada ao apagamento, mas deve-se perceber a diferença entre os olhares. $\mathrm{O}$ juízo de valor sobre os sertanejos, perceptíveis nos trechos anteriores, ecoam os já conhecidos e depreciativos comentários de Euclides na narrativa sobre Canudos. "Ambição 
maldita, fraqueza moral e credulidade infantil" quase justificam a condição em que o indivíduo se encontra. O ser decaído encontra no inferno verde o castigo para seus erros.

Antes do contraponto de Ferreira de Castro, vale assinalar como a abordagem de Euclides deixou herança. Carlos de Vasconcelos, na introdução ao seu romance Deserdados, declara que seu objetivo é mostrar

em suas linhas originalíssimas, a vida amazônica que Rodolfo Teófilo, Alberto Rangel e Euclides da Cunha apenas esboçaram _ o primeiro por falta de conhecimento direto do meio, e os dois outros talvez por motivo de sua exígua permanência no interior. (VASCONCELOS, 1922)

No romance, a fuga do sertanejo pela terra árida é o início de um caminho de perdição, com urubus devorando as vísceras dos que caem e esperando, sem muita paciência, que mães desistam de levar nos braços filhos já mortos. As passagens carregadas de armadilhas e animais devoradores continuam pelos rios, donde surgem monstros que arrastam os homens para as profundezas. Mas a marca naturalista, que faz esquecer um certo lirismo parnasiano do início do livro, predomina na maior parte da narrativa, com o homem sucumbindo "aos mais primitivos e brutais instintos". Bestialismo, estupros, assassinatos e até mesmo uma canhestra tentativa de autópsia merecem descrições assustadoras. O que temos é o confronto de duas bestas, a floresta/inferno hostil e o homem decaído na sua condição de fera.

O seringueiro/escritor/jornalista Ferreira de Castro, que não poderia ser acusado de desconhecimento do meio ou de exígua permanência na região, nos apresenta um panorama em que não falta violência, perigo, medo, desvios e loucura. Mas nenhum desses elementos supera a força da solidariedade, nega ou diminui a condição humana dos personagens. Se um olhar eurocêntrico sobre o "meio exótico" e a presença de aspectos naturalistas podem ser identificados em $A$ selva, da mesma forma encontramos um desvio dessas rotas no conjunto do romance, seja olhando-o individualmente, seja comparando-o com os trabalho de Euclides ou Vasconcelos. O meio, sua descrição e influência sobre os indivíduos também se apresentam em $A$ selva, mas o homem que nos surge no romance, até pela variedade de tipos, não está condenado a se revelar monstro ao atravessar o portal da floresta. Ao contrário do que indicavam as teorias deterministas, em vários momentos do romance encontramos a emergência de manifestações daquilo que de melhor o homem teria. A "fraqueza moral", que segundo Euclides refrearia a rebeldia dos seringueiros é 
claramente contestada pelo final do romance de Castro. Cabe ao personagem Tiago, cuja condição humana é ainda mais desvalorizada pelo dono do seringal, manifestar sua revolta contra o que julgara um excesso de Juca Tristão, que punira com uma surra os seringueiros que tentaram escapar de seu domínio. Tiago, quando questionado sobre os motivos que o levaram a atear fogo ao barracão central do seringal, ocasionando a morte do patrão, responde:

Eu também gostava muito do patrão. Ele podia até me matar que eu não fugia. Era mesmo amigo dele. Mas seu Juca se desviou... Estava a escravizar os seringueiros. Tronco e peixe-boi no lombo, só nas senzalas. E já não há escravatura... [...]

Eu é que sei o que é ser escravo! Ainda tenho aqui, nas costas, o sinal do chicote do feitor, lá no Maranhão. Branco não sabe o que é liberdade como negro velho. Eu é que sei. (CASTRO, 1972, p.305)

Quem esperaria de um sujeito afeito à submissão a defesa da liberdade de outros?

Os caminhos de Euclides da Cunha e Ferreira de Castro se encontram na denúncia de uma realidade tenebrosa, na apresentação de um espaço, a região amazônica, ainda hoje pouco conhecida. Mas a direção seguida por cada um é bastante distinta. Euclides se dá a missão de escrever a história de uma terra. Ferreira de Castro contribui com a escrita dessa história, mas a função do lembrar e do escrever do romancista

não se trata somente de não esquecer do passado, mas também de agir sobre o presente. A fidelidade ao passado, não sendo um fim em si, visa a transformação do presente. (GAGNEBIN, 2006, p.55)

A ambição, e aqui não a chamamos de maldita, do imigrante Ferreira de Castro era a mesma dos migrantes nordestinos, conseguir o seu quinhão da riqueza gerada pela exportação da borracha. Nem ele, nem a maioria dos que assumiram a empreitada na floresta, como hoje registra a história, conseguiu seu objetivo.

A "obra que há de registrar a tremenda caminhada dos deserdados através dos séculos, em busca de pão e de justiça" (CASTRO, 1972, p.21), continua a ser escrita na Literatura e na História, continua a depender da memória e dos testemunhos, das cartas, dos ensaios e dos romances. 


\section{Referências bibliográficas}

BOSI, Alfredo. Literatura e resistência. São Paulo: Companhia das Letras, 2002.

CASTRO, Ferreira de. A selva, São Paulo: Editora Verbo, 1972.

CUNHA, Euclides da. Obra completa vol. I. Rio de Janeiro: Companhia José Aguilar Editora, 1966.

GAGNEBIN, Jeanne Marie. Lembrar escrever esquecer. São Paulo: Ed. 34, 2006.

GALEANO, Eduardo. As veias abertas da América Latina, $38^{\mathrm{a}}$ ed. Rio de Janeiro: Paz e Terra, 1988.

GALVÃO, Walnice Nogueira, GALOTTI, Oswaldo.org. Correspondência de Euclides da Cunha. São Paulo: Editora da Universidade de são Paulo, 1997.

PRADO, Maria Lígia Coelho. Borracha na economia brasileira da primeira república. In: Fausto, B, Org. Historia Geral da Civilização Brasileira: o Brasil Republicano: Estrutura de Poder e Economia (1889-1930). Rio de Janeiro: Bertrand Brasil, 1989.

VASCONCELOS, Carlos de. Deserdados: romance da Amazônia. Rio de Janeiro: Editora Leite Ribeiro, 1922. 